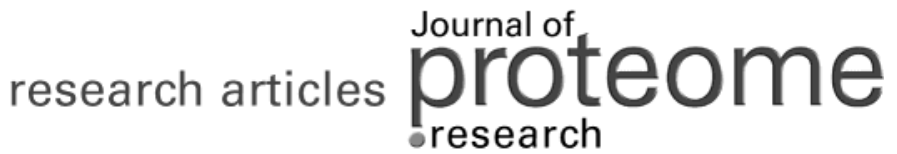

\section{Riboproteomics of the Hepatitis C Virus Intemal Ribosomal Entry Site}

\author{
Henry Lu, Weiqun Li, William Stafford Noble, ${ }^{\dagger}$ Donald Payan, and D. C. Anderson*, \\ Rigel, Inc., South San Francisco, California 94066, Department of Genomic Science, University of Washington, \\ Seattle, Washington 98195, and Institute of Molecular Biology, University of Oregon, Eugene, Oregon 97403
}

Received February 8, 2004

Hepatitis $\mathrm{C}$ virus (HCV) protein translation is mediated by a cis-acting RNA, an internal ribosomal entry site (IRES), located in the $5^{\prime}$ nontranslated region of the viral RNA. To examine proteins bound to the IRES, which could include proteins important for its function as well as potential drug targets, we used shotgun peptide sequencing to identify proteins in quadruplicate protein affinity extracts of lysed Huh7 cells, obtained using a biotinylated IRES. Twenty-six proteins bound the HCV IRES but not a reversed complementary sequence RNA or vector RNA controls. These included five ribosomal subunits, nine eukaryotic initiation factor 3 subunits, and novel interacting proteins such as the cytoskeletal-related proteins actin, FHOS (formin homologue overexpressed in spleen) and MIP-T3 (microtubule interacting protein that associates with TRAF3). Other novel HCV IRES-binding proteins included UNR (upstream of N-ras), UNR-interacting protein, and the RNA-binding proteins PAI-1 (plasminogen activator inhibitor1) mRNA binding protein and Ewing sarcoma breakpoint 1 region protein EWS. A large set of additional proteins bound both the HCV IRES and a reversed complementary IRES sequence control, including the known HCV interactors PTB (polypyrimidine tract binding protein), the La autoantigen, and nucleolin. The discovery of these novel HCV IRES-binding proteins suggests links between IRES biology and the cytoskeleton, signal transduction, and other cellular functions.

Keywords: hepatitis C $\bullet$ IRES $\bullet$ RNA $\bullet$ binding proteins $\bullet$ shotgun peptide sequencing • machine learning

\section{Introduction}

As many as 170 million people worldwide may be infected by the hepatitis $C$ virus. ${ }^{1}$ Infection can lead to hepatitis, which cannot be efficiently cured, and is a major risk factor for liver cirrhosis and hepatocellular carcinoma. ${ }^{2-3}$ Hepatitis $C$ virus (HCV) is a single-stranded RNA virus containing a structured internal ribosomal entry site (IRES) ${ }^{4}$ in the $5^{\prime}$-noncoding region of the viral RNA. This IRES mediates cap-independent initiation of translation of the viral polyprotein during virus replication. The HCV IRES interacts with eukaryotic initiation factor $3,^{5}$ elF2B $\gamma$ and elF $2 \gamma, 6$ GTP, initiator tRNA and the 405 ribosomal subunit, ${ }^{7}$ to form a $43 \mathrm{~S}$ preinitiation complex, ${ }^{8}$ a property that differs from the majority of cellular mRNAs. ${ }^{9}$ The HCV IRES recruits this complex to an internal initiation codon in the viral mRNA to form a $48 \mathrm{~S}$ complex, with the help of cellular transacting factors. Other proteins reported to interact with the HCV IRES include polypyrimidine tract binding protein, ${ }^{10}$ the La autoantigen, ${ }^{11}$ hnRNP-L, ${ }^{12}$ the proteasome subunit PSMA7, ${ }^{13}$ and nucleolin. ${ }^{14}$ The mechanism of HCV IRES mediated translation, particularly the involvement of host protein factors, remains elusive. A survey of IRES-binding proteins by a riboproteomics approach may provide valuable information for the mechanism underlining HCV IRES-mediated cap-indepen-

\footnotetext{
* To whom correspondence should be addressed

† University of Washington.

₹ University of Oregon.
}

dent translation, and could identify potential drug targets among proteins tightly and selectively coupled to translation of viral mRNA.

Tandem mass spectrometry-based peptide sequencing has revolutionized the analysis of cellular proteins. Microcapillary hplc-tandem mass spectrometry peptide sequencing was initially utilized by Hunt et al., ${ }^{15}$ and more recently has been used to identify proteins in complex mixtures, ${ }^{16}$ individual protein complexes, ${ }^{17-19}$ interacting proteins for a large number of tagged protein baits in yeast, ${ }^{20-21}$ interactors of novel peptides found in cellular screens of large peptide libraries, ${ }^{22}$ for large scale analysis of the yeast proteome ${ }^{23}$ and of the nucleolus. ${ }^{24}$ This approach has not, to our knowledge, been applied to examine proteins interacting with IRESs.

Here, we extend earlier work on protein affinity extracts 22,25 to the identification of RNA-binding proteins, and modify our data analysis to include proteins common to two affinity extracts in addition to proteins unique to a single extract. We use the program SEQUEST ${ }^{26}$ for database searches, the Oracle database Medusa ${ }^{22}$ for comparison to control extracts, and support vector machine calculations ${ }^{27}$ to predict correct matches between 13 parameter mass spectrometry data and databasematched peptide sequences. Affinity extracts of the 330 base HCV IRES RNA sequence, a control reversed complementary IRES sequence, and a control 347 base vector-derived RNA sequence, were examined in quadruplicate to ensure reproducibility of the results. Proteins uniquely present in the HCV IRES 
affinity extracts were defined by comparison of IRES affinity extracts with quadruplicate reversed complementary sequence extracts. Proteins common to the hepatitis $C$ extract and the reversed IRES sequence were also examined. In addition to identification of most of the known HCV IRES-interacting proteins, we identify new IRES-binding proteins. Some are known to interact with other IRESs, whereas others are novel binding partners of the HCV IRES.

\section{Experimental Section}

Construction of Plasmids. A DNA fragment encoding the HCV IRES (nucleotides 20 to 377 of the HCV type 1b genomic RNA) was amplified from an HCV replicon plasmid pFKI389neo/ NS3-3'/adapt3-5A (kindly provided by Dr. Ralf Bartenschlager) by PCR using primers HLR-14 and HLR-15 (see below). The PCR product was purified with QIAquick PCR Purification Kit (Qiagen) by following the manufacturer's instructions, and inserted into plasmid vector pCDNA3.1 (Invitrogen) linearized by the restriction enzyme EcoRV. The resulting plasmids have the HCV IRES insert in either orientation: the plasmids expressing HCV IRES RNA were designated pCD-377+, whereas those expressing reverse complementary IRES RNA were designated pCD-377-.

HLR-14: CGACACTCCACCATAGATCACTCC

HLR-15: TTTGGTTTTCTTTGAGGTTTAGGATTCGTGC

HLR-17: CGCTAGCCAGCTTGGGTCTCCCAG-BIOTIN

In Vitro RNA Transcription. Both plasmids PCD-377+ and pCD-377- were linearized by EcoRI to produce DNA templates for T7 runoff transcription of the HCV IRES RNA or its reverse complementary RNA (RC-IRES). Plasmid pCDND3.1 was linearized by the restriction enzyme Bbsl, and used as a template to transcribe a 347 nt-long, vector-derived RNA as an experimental control. In vitro RNA transcription was performed using the RiboMax T7 Transcription kit (Ambion, Austin, TX), and the RNA products were further purified with Rneasy columns (Qiagen, city) and quantified using a UV spectrometer.

Affinity Extractions Using Biotin-Tagged RNAs. Huh7 cells, capable of supporting HCV RNA translation and replication, ${ }^{28}$ were grown in Dulbecco's modified Eagle's medium (Gibco/ BRL Life Technologies, Inc., Gaithersburg, MD) supplemented with $10 \%$ fetal bovine serum, L-glutamine, nonessential amino acids, penicillin, and streptomycin. The Huh7 cells were scraped off of the culture flasks in phosphate buffered saline (PBS). The cells were washed with cold PBS $4 \times$ and pelleted by centrifugation at $1000 \times \mathrm{g}$. Cells were lysed in ice-cold hypotonic buffer (10 mM K-Hepes, pH 7.5, 10 mM KOAc, 1.5 $\mathrm{mM} \mathrm{MgOAc}$, and $2.5 \mathrm{mM}$ dithiothreitol). Nuclei and other cell debris were removed by centrifugation at $1000 \times \mathrm{g}$ for $5 \mathrm{~min}$. The supernatant was subject to further centrifugation at 10000 $\times \mathrm{g}$ for $20 \mathrm{~min}$. The supernatant (cytoplasm fraction S10) was stored in small aliquots at $-80^{\circ} \mathrm{C}$.

Each in vitro transcribed RNA was annealed to the biotinylated oligo HLR-17 in the presence of $270 \mathrm{mM} \mathrm{NaOAc}(\mathrm{pH}$ 5.5). Free HLR-17 and salt were removed by using an RNeasy kit (Qiagen, Valencia CA). HLR-17 anneals to a 24-nt RNA sequence common to in vitro transcripts of HCV IRES, RC-RNA, and the vector RNA, attaching the biotin tag to the transcripts for affinity purification of RNA-binding proteins.

Biotin-tagged HCV IRES, reversed-complementary RNA, and the vector control RNA were incubated with the Huh7 S10 extract in a buffer containing 1X PBS, $70 \mathrm{mM} \mathrm{KOAc,} 2.5 \mathrm{mM}$ MgOAc, $2 \mathrm{mM}$ DTT, $1 \mathrm{mM}$ ATP, and 40 units of RNasin at 30 $C$ for $20 \mathrm{~min}$. RNA-protein complexes were affinity-purified employing immobilized streptavidin-agarose beads. The RNA protein/beads complexes were washed 3 times with cold PBS containing $70 \mathrm{mM} \mathrm{KOAc}, 2.5 \mathrm{mM} \mathrm{MgOAc}$, and 40 units of RNasin.

Mass Spectrometry. A fraction of an affinity extracted complex was run on a 1D SDS-PAGE gel and protein bands unique to the HCV IRES were excised, digested using trypsin ${ }^{29}$ and identified by microcapillary LC-MS/MS on an LCQ mass spectrometer (ThermoFinnigan, San Jose, CA). Two blank gel areas were run as controls. The in-gel digests were introduced into the LCQ using a pico-frit column (New Objective, Woburn MA) self-packed with $5 \mathrm{~cm}$ of $\mathrm{C} 18$ resin. The rest of the affinity extract in $8 \mathrm{M}$ urea was heated at $90^{\circ} \mathrm{C}$ for $10 \mathrm{~min}$., reduced by dithiothreitol and alkylated by iodoacetamide. The solution was diluted to $4 \mathrm{M}$ urea and digested with lys- $\mathrm{C}$ endoprotease (Boehringer Mannheim, Germany) at $37^{\circ} \mathrm{C}$ for $12 \mathrm{~h}$; this allows digestion under more denaturing conditions, with potentially more complete proteolysis for some proteins, than under conditions used for trypsin. This was followed by dilution to 2 $M$ urea and digestion with modified trypsin (Boehringer Mannheim, Germany) at $37^{\circ} \mathrm{C}$ also for $12 \mathrm{~h}$. The peptide mixtures were desalted on an offline $1 \mathrm{~mm}$ i.d. $\times 5 \mathrm{~mm}$ microbore C18 guard column (GraceVydac, Hesperia, CA). Half of the resuspended sample was injected onto a biphasic column packed in-house with $4 \mathrm{~cm}$ of Polysulfoethyl Aspartamide strong cation exchange (SCX) media (PolyLC, Columbia, MA) and $12 \mathrm{~cm}$ of 3 micron particle Aquasil C18 reversed phase media (Keystone Scientific, Bellefonte, PA). Two-dimensional strong cation exchange-C18 reversed phase LC-MS/MS experiments were performed on a quadrupole time-of-flight mass spectrometer (Micromass, Manchester, UK). The affinity extraction experiments were run in quadruplicate and each extract was analyzed separately by $2 \mathrm{D}$-LC-MS/ MS to check the reproducibility of the identified proteins. Only proteins that appeared in at least 2 out of the 4 affinity extractions were considered to be specific IRES binding partners. The MS/MS data were analyzed by SEQUEST (ThermoFinnigan, San Jose, CA). All SEQUEST results were exported into the Medusa data system. 22 Medusa summarized the quadruplicate 2D-LC-MS/ MS data, evaluated each peptide identification, subtracted the proteins in the control experiments, and generated a final report including a list of identified proteins, the reproducibility of each protein, other proteins that share the same peptides, and related bioinformatics. The Protein Abundance Index ${ }^{30}$ was calculated for each protein as the ratio of the observed number of tryptic peptides to the total observable tryptic peptides, which were derived by in silico digestion of each protein using Protein Prospector (http://prospector.ucsf.edu/ucsfbin4.0/ mssearch.cgi) allowing for oxidized methionine, alkylated cysteine, 2 missed tryptic cleavage sites, and a minimum peptide length of 5 residues.

Support Vector Machine Learning. The SVM computes, for each candidate peptide assignment produced by SEQUEST, the probability that the given peptide generated the observed spectrum. These probablities are computed by first training the SVM, using a separate data set, to discriminate between correct and incorrect peptide-spectrum pairs. In this case, the SVM was trained using 1549 peptide-spectrum pairs predicted by SEQUEST from data on the same type of QTOF instrument from a tryptic sample derived from 45 known proteins. Among the 1549 peptide-spectrum pairs, 1017 are correct matches (i.e., peptides that occur in the sample proteins), and 532 are incorrect matches. Generation of this training set is described 


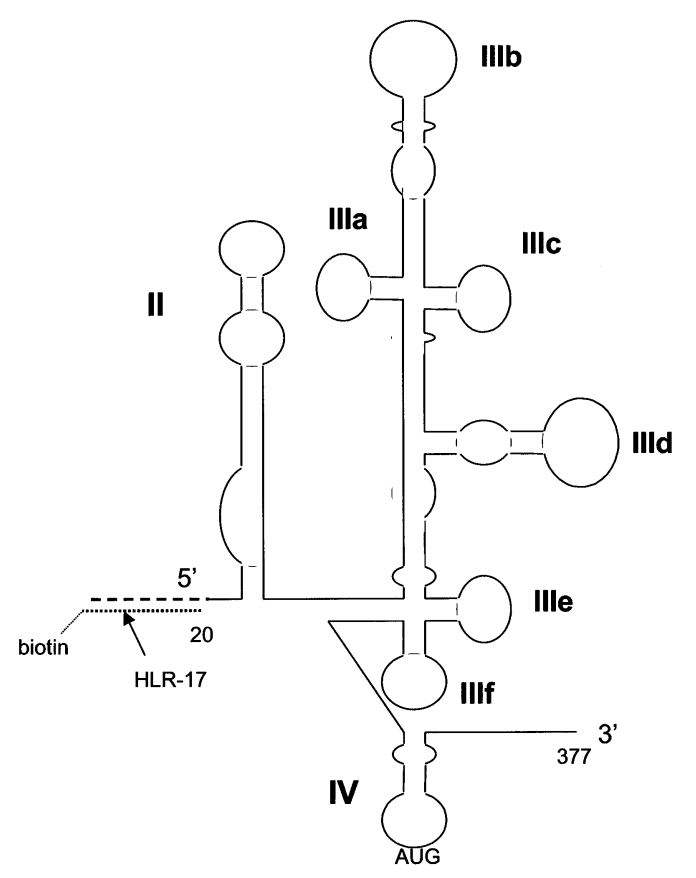

Figure 1. Secondary structure of the HCV IRES, modeled after that shown by Lukavsky et al. ${ }^{34}$ The IRES is divided into 4 domains. Parts of domain II and III are thought to bind the $40 \mathrm{~S}$ ribosome while other parts of domain III interact with elF3. The biotinylated primer (dotted line) used for affinity extraction binds a 24 base nucleotide (dashed line) added to the $5^{\prime}$ end of the IRES.

in detail. ${ }^{27}$ Each spectum-peptide pair is characterized via a vector of 13 features, including properties of the observed spectrum (total peptide mass, charge, total ion current and peak count), properties that compare the observed and theoretical spectra (mass difference, percent of ions matched, percent of peaks matched, percent of fragment ion current matched, SEQUEST Sp score, cross-correlation coefficient) and properties that compare this pair with other pairs in the database (cross-correlation rank, change in cross-correlation relative to the second-ranked peptide, and percent sequence identity relative to the second-ranked peptide). Using this collection of 1549 positively and negatively labeled 13-element vectors, the SVM is trained using the freely available Gist software (http://microarray.cpmc.columbia.edu/gist) to discriminate between correct and incorrect matches. A small portion of the training set (10\%) is held out of the initial SVM training and is used subsequently to fit a sigmoid curve to the SVM discriminant values, thereby yielding probability estimates. Finally, to assign a probability to a candidate spectrumpeptide assignment produced by SEQUEST, the trained SVM takes as input the corresponding 13-element vector and produces as output a probability that the spectrum was generated by the given peptide.

\section{Results}

Figure 1 illustrates the secondary structure of the HCV IRES element employed in the riboproteomics analysis. The HCV IRES contains the HCV genome sequence from nucleotides 20 to 377 , that is functional in HCV IRES-driven translation. ${ }^{31-32}$ The IRES contains four domains. The $40 \mathrm{~S}$ ribosome binds to domains III and IV, ${ }^{33}$ while domain II is required for IRES activity and may modulate $40 \mathrm{~S}$ subunit conformation. ${ }^{34}$ elF3

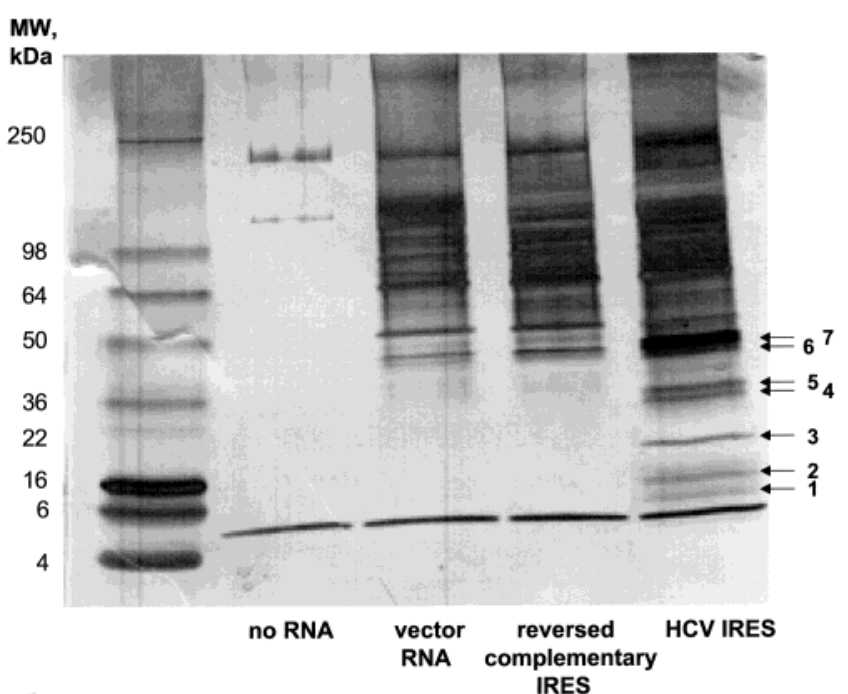

Figure 2. SDS-PAGE gel of the HCV IRES affinity extract compared to control extracts. A biotinylated primer was hybridized to the HCV IRES in Huh-7 cell lysates and extracted with streptavidin beads. The reversed-complementary strand sequence of the IRES, and a PCD vector RNA sequence, were used as controls. Multiple bands below $50 \mathrm{kDa}$ present only in the IRES affinity extract were visualized by silver staining, and subjected to in-gel tryptic digestion and tandem mass spectrometry for identification of the proteins present in the bands. Comparison of the upper half of the gel lanes suggests that there are many proteins which bind to both the HCV IRES and the reversed complementary IRES, as well as to the vector-derived RNA.

may bind to domains III b and IIIc. ${ }^{35}$ The RC-RNA does not possess any IRES activity (data not shown). The 347 nucleotide vector-derived RNA served as an additional control. All three RNA species had a vector-derived 24-nucleotide sequence at their $5^{\prime}$ end that allowed annealing to the biotinylated oligonucleotide HLR-17. Using BlastN 2.2.6, an expectation level of 1000 , and omitting the common bases at the $5^{\prime}$ ends, there was no detectable pairwise homology between the HCV IRES, reversed complementary sequence, and vector control sequences. It is possible that the reversed complementary and vector sequences could still have complex RNA structures, but due to the low levels of sequence homology, they likely would be different than the HCV IRES structure.

Figure 2 shows a 1D gel comparing HCV IRES, RC-RNA, and vector RNA affinity extracts from lysed Huh7 cells. An affinity extract using only agarose-streptavidin beads served as an additional control. After extraction in Huh7 cell lysate the beads were washed with cold PBS containing potassium and magnesium acetate and the RNAse inhibitor RNasin. Other ionic and divalent cation conditions could be used to explore the protein binding dependence of these variables. All three RNA extracts contained bands not present in the beads-alone control, as well as bands in common, especially above ca. 36 $\mathrm{kDa}$. The HCV IRES extract had a number of unique bands below $50 \mathrm{kDa}$. These were excised, in-gel digested by trypsin, and identified by LC/MS/MS analysis using a spray tip capillary column (Table 1). The 40 S ribosomal proteins S3, S5, S7, S18, p40, and actin were identified as associated with the HCV IRES. Band 3 contained two proteins of very similar size, while band 4 contained one protein of the expected mass of ca. $36 \mathrm{kDa}$ and a smaller ribosomal subunit of $27 \mathrm{kDa}$. Peptides consistent with $\beta$ - or $\gamma$-actin were observed in both bands 6 and 7 . It is 
Table 1. In-Gel Digest Identified HCV IRES Binding Proteins Absent in Reversed IRES and PCD Vector Controls

\begin{tabular}{|c|c|c|c|c|c|}
\hline band & protein & peptides & $\mathrm{MW}_{\text {theor }}$ & $\mathrm{MW}_{\text {obs }}$ & $\begin{array}{c}\text { SVM } \\
\text { probability }\end{array}$ \\
\hline 2 & $40 S$ ribosomal protein S18 & $\begin{array}{l}\text { AGELTEDEVER } \\
\text { LREDLER }\end{array}$ & 17.7 & 10 & $\begin{array}{l}0.96 \\
0.38\end{array}$ \\
\hline 3 & $40 S$ ribosomal protein $\mathrm{S7}$ & $\begin{array}{l}\text { VHLDKAQQNNVEHK } \\
\text { HWFIAQR, RILPKPTR }\end{array}$ & 21.9 & 19 & $\begin{array}{l}0.93 \\
0.39,0.48\end{array}$ \\
\hline & $40 \mathrm{~S}$ ribosomal protein S5 & $\begin{array}{l}\text { RQAVDVSPLR } \\
\text { YLPHSAGR }\end{array}$ & 22.8 & & $\begin{array}{l}0.86 \\
0.87\end{array}$ \\
\hline 4 & $\begin{array}{l}\text { 40S ribosomal protein S3 } \\
\text { dual specificity phosphatase } 12\end{array}$ & $\begin{array}{l}\text { GLCAIAQAESLR } \\
\text { MTPSSMLTTGR }\end{array}$ & $\begin{array}{l}26.7 \\
37.7\end{array}$ & 36 & $\begin{array}{l}0.88 \\
0.55\end{array}$ \\
\hline 6 & $\beta$ - or $\gamma$ actin & $\begin{array}{l}\text { VAPEEHPVLLTEAPLNPK } \\
\text { plus one other peptide }\end{array}$ & 41.2 & 45 & 0.88 \\
\hline 7 & $\beta$ - or $\gamma$-actin & $\begin{array}{l}\text { SYELPDGQVITIGNER } \\
\text { GYSFTTTAER } \\
\text { plus } 2 \text { other peptides }\end{array}$ & 41.2 & 47 & $\begin{array}{l}0.85 \\
0.96\end{array}$ \\
\hline & $40 \mathrm{~S}$ ribosomal protein SA/p40 & AIVAIENPADVSVISSR & 32.7 & & 0.84 \\
\hline
\end{tabular}

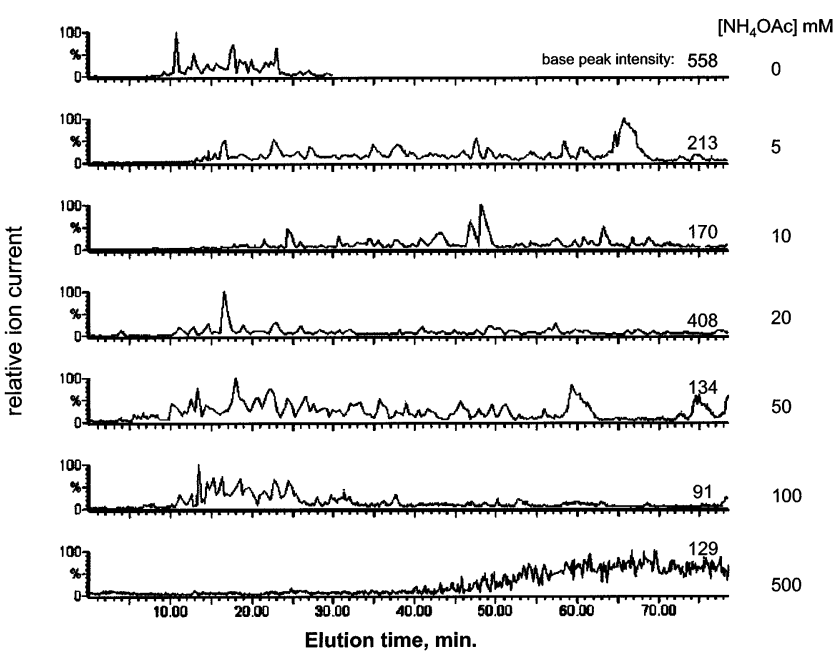

Figure 3. Base peak intensity chromatograms of individual strong cation exchange 2D LC/MS/MS fractions. An affinity extract of the hepatitis C IRES was digested with lys C endoprotease and trypsin, and loaded on a biphasic capillary strong cation exchange/C18 reversed phase column. The first phase was eluted with increasing concentrations of ammonium acetate, and after each step elution an $\mathbf{8 0}$ min gradient elution of the peptides off the second (reversed) phase of the column was done. Tryptic peptides eluted off in all fractions but were most abundant in fractions eluting at $100 \mathrm{mM}$ salt or less. In total $3591 \mathrm{MS} / \mathrm{MS}$ spectra were collected, representing 1090 unique tryptic peptides. After subtraction of MS/MS spectra in control runs and filtering for peptides present in at least two of four affinity extracts, proteins uniquely present in the HCV IRES extract were identified (Table 2).

unclear why actin was identified in two bands, but possible that the differences could be due to the presence of both $\beta$ and $\gamma$ actin, or a covalent modification ${ }^{36}$ of actin. There may be additional HCV IRES-unique bands above $50 \mathrm{kDa}$ that are difficult to detect under these conditions; thus, micro-capillary $\mathrm{LC} / \mathrm{MS} / \mathrm{MS}$ was used to further examine proteolytic digests of each affinity extract.

Figure 3 shows the two-dimensional capillary hplc elution of tryptic peptides from a digest of the entire HCV IRES affinity extract from lysed Huh7 cells. Each chromatogram represents elution of one strong cation exchange fraction over the C18 capillary reversed phase column, and is normalized to the ion current of the largest peptide eluted, indicated as the base peak intensity at the right edge of the chromatogram. A total of 7 fractions were eluted. MS/ MS spectra from 3591 peptides were collected, representing 1090 unique peptides. While numerous proteins of molecular weight below $50 \mathrm{kDa}$, such as ribosomal proteins, were observed, other IRES-unique proteins up to ca. $135 \mathrm{kDa}$, that would be difficult to visualize in the Figure 2 gel, were also identified.

Table 2 lists 2D LC/MS/MS-identified proteins uniquely present in the HCV IRES affinity extract. The reproducibility of identification for each protein is listed, as well as the number of unique peptides identifying each protein, and the SVMcalculated probability of correct sequencing for examples of peptides used to identify each protein. The reproducibility of individual peptides varied from a presence in 1 to 4 of 4 extracts. The relative amount of each protein was roughly estimated using the protein abundance index, ${ }^{30}$ which is the ratio of the number of tryptic peptides identified here (in this case by SEQUEST) to those that could theoretically be identified using identical SEQUEST search conditions, for example allowing possible met oxidation, cys alkylation, and a maximum of 2 missed tryptic cleavage sites per peptide. In a number of cases, the presence of a larger number of identified peptides correlates with increased abundance of the corresponding protein. On the basis of 13 parameter support vector machine analysis of the peptides listed for these proteins, all peptides had a high probability of a correct match to the SEQUESTselected database peptide used for the identification. Thus, proteins identified by only a single peptide with a high probability of being correctly sequenced should be well identified, as long as the peptide is present in the sequence of that protein and not in other proteins. The reproducibility of occurrence of individual peptides varied from presence in all four affinity extracts to presence in one of four extracts. The reproducibility listed is for identification of the protein and not for individual peptides.

Identified proteins in Table 2 include both expected proteins and novel interactors. In the former category were nine of the twelve known subunits of eukaryotic initiation factor 3,5 identified by from 3 to 14 peptides for each subunit, and two ribosomal proteins identified as $40 \mathrm{~S}$ ribosome subunit protein S18 and 60 S subunit L29. A number of novel HCV IRESinteracting proteins were also identified. These included RNA binding proteins such as UNR (upstream of N-ras), ${ }^{37}$ the type 1 plasminogen activator inhibitor mRNA binding protein PAI1, and the Ewing sarcoma breakpoint region 1 protein EWS, which contains an RRM RNA recognition motif and a zinc finger RNA binding region. PNAS- 125 and the hypothetical protein XP 034431 both contain predicted PINT domains. Several novel proteins that may be connected to signaling 
Table 2. Unique Protein Binding Partners of the HCV IRES Identified Using 2D Strong Cation Exchange-Reversed Phase Microcapillary LC/MS/MS on a QTOF Mass Spectrometer

\begin{tabular}{|c|c|c|c|c|c|}
\hline $\begin{array}{l}\text { identified } \\
\text { protein }\end{array}$ & $\begin{array}{l}\text { reproducibility } \\
\text { of protein } \\
\text { identification }\end{array}$ & peptide example & $\begin{array}{l}\text { total unique } \\
\text { peptides }\end{array}$ & $\begin{array}{l}\text { SVM prob. of } \\
\text { listed peptide }\end{array}$ & $\begin{array}{c}\text { protein } \\
\text { abundance } \\
\text { index }\end{array}$ \\
\hline elF3 subunit 2 & 4 of 4 & GHFGPINSVAFHPDGK & 9 & 0.98 & 0.11 \\
\hline subunit 5 & 4 of 4 & TMGVMFTPLTVK & 5 & 0.97 & 0.078 \\
\hline subunit 7 & 4 of 4 & YNFPNPNPFVEDDMDK & 14 & 0.97 & 0.070 \\
\hline subunit 11 & 4 of 4 & GIDRYNPENLATLER & 3 & 0.96 & 0.064 \\
\hline subunit 6 & 4 of 4 & LGHWVM GNNAVSPYQQVIEK & 8 & 0.97 & 0.054 \\
\hline subunit 8 & 4 of 4 & DAHNALLDIQSSGR & 7 & 0.98 & 0.054 \\
\hline subunit 9 & 4 of 4 & GYIFLEYASPAHAVDAVK & 12 & 0.99 & 0.047 \\
\hline p40 subunit & 4 of 4 & HELLSLASSNHLGK & 4 & 0.97 & 0.033 \\
\hline p110 subunit & 4 of 4 & GTEITHAWVIK & 5 & 0.96 & 0.021 \\
\hline UNR-interacting protein & 4 of 4 & YDYNSGEELESYK & 4 & 0.97 & 0.053 \\
\hline UNR protein & 4 of 4 & DQFGFINYEVGDSK & 5 & 0.97 & 0.038 \\
\hline $\begin{array}{l}\text { PAl-1 mRNA } \\
\text { binding protein }\end{array}$ & 4 of 4 & FDQLFDDESDPFEVLK & 2 & 0.92 & 0.034 \\
\hline XP_034431 & 4 of 4 & VAASCGAIQYIPTELDQVR & 4 & 0.94 & 0.031 \\
\hline PNAS-125 & 4 of 4 & DFIDSLGLLHEQNMAK & 2 & 0.96 & 0.027 \\
\hline ribosomal protein L29 & 3 of 4 & AQAAAPASVPAQAPK & 2 & 0.93 & 0.018 \\
\hline XP 070867 & 2 of 4 & KQQQPNEGIK & 1 & 0.77 & 0.017 \\
\hline $\mathrm{FH} \overline{1} / \mathrm{FH} 2$ protein $\mathrm{FHOS}$ & 3 of 4 & KPSSEEGK & 4 & 0.72 & 0.014 \\
\hline ribosomal protein S18 & 2 of 4 & YSQVLANGLDNK & 1 & 0.95 & 0.012 \\
\hline XP 076816 & 2 of 4 & VASSIIILGHIK & 2 & 0.86 & 0.011 \\
\hline $\begin{array}{l}\text { Ewing sarcoma } \\
\text { breakpoint protein EWS }\end{array}$ & 2 of 4 & AGDWQCPNPGCGNQNFAWR & 2 & 0.96 & 0.0093 \\
\hline MIP-T3 & 2 of 4 & PPLTEKLLSK & 1 & 0.74 & 0.0034 \\
\hline NMDA receptor subunit $2 \mathrm{C}$ & 2 of 4 & DSGGLDEISSVAR & 1 & 0.86 & 0.0039 \\
\hline
\end{tabular}

functions were also identified, including the UNR-interacting protein MAWD (MAP activator with WD repeats) and the formin homology domain protein FHOS. ${ }^{38}$ No hepatitis $C$ virus proteins were detected in the HCV IRES affinity extract.

Table 3 identifies proteins common to the HCV IRES and reversed IRES sequence extracts. Overall 69 proteins were identified in several categories, including the known HCV IRES interacting factors, La autoantigen, PTB and nucleolin. In addition to the 9 elongation initiation factors that bind selectively to the HCV IRES, 3 other factors also bind to the reversed sequence. Eighteen additional RNA binding proteins bound both sequences, including 4 polyA binding proteins. Nine hnRNPs, 3 tRNA synthetases, 3 DNA binding proteins, and 30 ribosomal proteins from both the small and large subunits bound both RNAs. The most abundant proteins common to the IRES and reversed complementary IRES extracts included the 3 RNA binding proteins hnRNP E2, CRDBP, hnRNP-U, and the three ribosomal proteins S13, S11, and S9.

\section{Discussion}

In this paper, we have examined the interacting proteins of the HCV IRES using in-gel digests of difference 1D gel bands, and $2 \mathrm{D} \mathrm{LC} / \mathrm{MS} / \mathrm{MS}$ analysis of quadruplicate affinity extracts. As an initial step, we have compared HCV IRES-binding proteins with proteins binding RNAs of significantly different sequence. We have not addressed the structural basis for interaction of these proteins with the HCV IRES. If proteins binding to other IRESs were compared, host factors specific for individual IRESs might be identified. Although sequence variability of the HCV IRES may not affect translation efficiency ${ }^{39}$ or have clinical significance, ${ }^{40}$ IRES sequence variants could have different host protein interactions, which could be examined for a correlation with other IRES functions.

In-gel digests and shotgun sequencing of affinity extracts can be complementary for the identification of interactors of a defined protein; ${ }^{41}$ here, each method identified unique IRES interactors. The overall picture of the HCV IRES that results from this analysis is of a structured RNA with 90 or more bound proteins, a quarter of which may bind specifically. A number of known IRES binding proteins have been identified, providing a level of validation of this riboproteomics analysis. We have also identified a number of novel HCV IRES-interacting proteins, discussed in detail below, which may suggest new associations between HCV IRES biology and cellular functions. The IRES interacting proteins can be divided into different functional or structural categories, as summarized in Figure 4. Some identified proteins belong to more than one category, suggesting that these functions may be linked. Interacting proteins identified here may bind directly to the IRES, which might be the case for RNA binding proteins, or may bind indirectly to another IRES-binding entity such as the ribosome or elf3.

The protein abundance index is thought to roughly reflect the relative amount of a protein that is present. ${ }^{30} \mathrm{HCV}$ IRESunique binding proteins have relative abundances spanning a 28-fold range. This range may be due to proteins binding to a single complex with a range of binding affinities (allowing weaker binders to be depleted during isolation), or due to the presence of more than one tightly bound complex, with each present at different levels. Different bound stoichiometries may further complicate analysis. Many IRES-unique interactors have relative abundances similar to those of the known HCV IRES binding proteins PTB, La and nucleolin, suggesting they could be present in the same IRES complex or in IRES complexes with similar stoichiometries. Eukaryotic initiation factor 3 is a $600 \mathrm{kDa}$ multisubunit complex that binds mRNA to the 40S ribosome, and binds the HCV IRES stem loop III with a Kd of 35 nM. ${ }^{35}$ Nine elF3 subunits were identified by from 3 to 14 peptides each, and included the most abundant IRES-unique interacting partners. The protein abundance indices for elF3 complex subunits are in a more restricted 5-fold range, 
Table 3. Proteins Binding to Both the HCV IRES and Reversed Complementary Sequence RNA

\begin{tabular}{|c|c|c|c|c|c|c|c|}
\hline identified protein & $\begin{array}{c}\text { total } \\
\text { unique } \\
\text { peptides } \\
>90 \% \text { prob. }\end{array}$ & $\begin{array}{l}\text { abundance } \\
>80 \% \text { prob. }\end{array}$ & $\begin{array}{l}\text { protein } \\
\text { index }\end{array}$ & identified protein & $\begin{array}{c}\text { total } \\
\text { unique } \\
\text { peptides } \\
>90 \% \text { prob. }\end{array}$ & $\begin{array}{l}\text { abundance } \\
>80 \% \text { prob. }\end{array}$ & $\begin{array}{l}\text { protein } \\
\text { index }\end{array}$ \\
\hline \multicolumn{4}{|c|}{ elongation factors } & \multicolumn{4}{|l|}{ tRNA synthetases } \\
\hline EIF1 $\alpha$ & 4 & 6 & 0.082 & isoleucyl-tRNA synthetase & 10 & 11 & 0.043 \\
\hline elF $1 \epsilon 1$ & $i$ & 2 & 0.047 & arg tRNA synthetase argrs & 4 & 6 & 0.035 \\
\hline eif2 subunit 3 & 2 & 2 & 0.015 & \multirow{2}{*}{\multicolumn{4}{|c|}{ DNA binding proteins }} \\
\hline \multicolumn{4}{|c|}{ known interacting proteins } & & & & \\
\hline nucleolin & 12 & 12 & 0.059 & dna binding protein mass $=35823$ & 3 & 5 & 0.055 \\
\hline PTB (hnRNP I) & 4 & 4 & 0.045 & single stranded dna-binding domain of human & & & \\
\hline autoantigen La & 5 & 5 & 0.020 & replication protein A, Rpa70 subunit & 2 & 2 & 0.051 \\
\hline \multicolumn{4}{|c|}{ RNA binding proteins } & DNA-binding protein B & 2 & 2 & 0.025 \\
\hline $\begin{array}{l}\text { poly }(\mathrm{rC}) \text { binding protein } 2 \\
\text { isoform b; hnRNP E2 }\end{array}$ & 6 & 8 & 0.119 & \multicolumn{4}{|l|}{ ribosomal proteins } \\
\hline mRNA binding protein CRDBP & 16 & 18 & 0.109 & S13 & 3 & 4 & 0.127 \\
\hline IGF-II mRNA binding protein 3 & 12 & 13 & 0.091 & S11 & 4 & 7 & 0.111 \\
\hline IGF-II mRNA binding protein 2 & 6 & 9 & 0.079 & $40 S$ rib prot $S 9$ & 3 & 5 & 0.107 \\
\hline staufen isoform b & 7 & 9 & 0.071 & S3 & 5 & 7 & 0.090 \\
\hline polyA binding protein II human & 3 & 5 & 0.050 & L23a & 2 & 5 & 0.088 \\
\hline $\begin{array}{l}\text { poly-A binding protein cyto } \\
4 \text { inducible }\end{array}$ & 3 & 7 & 0.049 & L26 & 1 & 3 & 0.076 \\
\hline poly(rC)-binding protein 1 & 2 & 4 & 0.047 & S19 & 2 & 5 & 0.070 \\
\hline $\begin{array}{l}\text { nuclear factor assoc. with } \\
\text { dsRNA NFAR-1 }\end{array}$ & 6 & 8 & 0.047 & S16 & 2 & 3 & 0.068 \\
\hline rna binding motif protein 3 & 2 & 3 & 0.034 & 40 s rib prot s5 & 1 & 5 & 0.065 \\
\hline thyroid autoantigen $70 \mathrm{kD} \mathrm{Ku}$ & 4 & 6 & 0.030 & $\mathrm{~S} 28$ & 1 & 2 & 0.056 \\
\hline RNA helicase II/Gu protein & 1 & 5 & 0.029 & L27a & 1 & 2 & 0.053 \\
\hline polyA binding protein 2 PABP2 & 2 & 2 & 0.016 & L4 & 3 & 6 & 0.051 \\
\hline $\begin{array}{l}\text { ATP-dependent RNA } \\
\text { helicase A, }\end{array}$ & 0 & 2 & 0.011 & rib prot S6, gi 15342049 & 2 & 4 & 0.041 \\
\hline nuclear dna helicase II & & & & L11 & 1 & 1 & 0.041 \\
\hline $\begin{array}{l}\text { similar to spermatid perinuclear } \\
\text { rna binding prot. }\end{array}$ & 2 & 2 & 0.011 & $\mathrm{~S} 27$ & 1 & 1 & 0.037 \\
\hline $\begin{array}{l}\text { similar to RNA binding protein } \\
\text { Musashi2-S }\end{array}$ & 1 & 1 & 0.008 & L3, gi 337580 & 5 & 8 & 0.037 \\
\hline polyA binding protein, cyto 1 & 1 & 1 & 0.008 & L24 & 0 & 1 & 0.033 \\
\hline AUF1 & 1 & 1 & 0.007 & similar to rib prot S3a; gi 12314263 & 2 & 4 & 0.033 \\
\hline \multicolumn{4}{|c|}{ hnRNP's } & L31 & 2 & 2 & 0.030 \\
\hline hnRNP U & 15 & 24 & 0.104 & similar to rib prot $\mathrm{L} 21$ & 0 & 1 & 0.028 \\
\hline hnRNP K & 7 & 8 & 0.075 & L23 & 1 & 2 & 0.028 \\
\hline hnRNP L & 7 & 7 & 0.064 & S12 & 1 & 1 & 0.024 \\
\hline hnRNP AO & 2 & 4 & 0.045 & $\mathrm{~s} 23$ & 1 & 1 & 0.021 \\
\hline similar to hnRNP Al & 0 & 1 & 0.043 & L17 & 1 & 2 & 0.020 \\
\hline similar to hnRNP A2/B1 & 1 & 1 & 0.027 & S26 & 1 & 1 & 0.020 \\
\hline hnRNP-D like & 1 & 2 & 0.015 & L6 & 1 & 1 & 0.016 \\
\hline hnRNP-G protein & 2 & 3 & 0.014 & L10 & 1 & 1 & 0.016 \\
\hline \multirow[t]{3}{*}{ similar to hnRNP C } & 0 & 1 & 0.007 & $\mathrm{~S} 2$ & 1 & 1 & 0.015 \\
\hline & & & & s10 & 1 & 1 & 0.014 \\
\hline & & & & acidic rib prot $\mathrm{PO}$ & 1 & 1 & 0.011 \\
\hline
\end{tabular}

consistent with the possibility they could reside here in an IRES bound complex. Two elF3 proteins, subunits 6 and p110, contain the $\mathrm{PCl}$ or PINT domain, which is also found in components of two other multi-protein complexes, the $26 \mathrm{~S}$ proteasome and the COP9 complex. This domain is also present in two novel HCV IRES interacting proteins discovered here, PNAS-125, an apoptosis/differentiation related gene, and XP_034431. Neither protein has an assigned function. The relative abundances of the four PINT domain proteins lie within a 2.6-fold range. Our results suggest that these proteins may be part of an elF3-HCV IRES complex.

In-gel digests of difference gel bands revealed a number of $40 \mathrm{~S}$ ribosomal proteins, which are involved in the translation of HCV proteins. Ribosomal protein S5, present in gel band 3, has been reported to interact with the HCV IRES. ${ }^{42}$ Two proteins in HCV IRES-unique gel bands, 40 S ribosomal proteins S5 and S3, were also present in the reversed IRES extract when examined by $2 \mathrm{D} \mathrm{LC} / \mathrm{MS} / \mathrm{MS}$, suggesting this latter technique might be more a more sensitive method to examine affinity extracts, and to further evaluate the specificity of the interactions. The elF3 p44 subunit interacts with the 4.1R protein, which anchors the membrane-cytoskeletal network structure, ${ }^{43}$ connecting the cytoskeleton and translation apparatus. The discovery of actin, present in two of the gel bands, also suggests a potential link between translation and the cytoskeleton (Figure 4). Actin and tubulin polymerization may be required for HCV RNA synthesis. ${ }^{44}$ The FH1/FH2 formin homology domain cytoplasmic protein FHOS was present in the tryptic digest of the entire affinity extract. $\mathrm{FH}$ proteins link cell signaling pathways to the actin cytoskeleton, and FHOS is thought to link the cytoskeleton with rho family GTPase signaling. ${ }^{45}$ An additional link to the cytoskeleton involves the protein MIP-T3, which binds both tubulin and TRAF3 and recruits TRAF3 to microtubules. ${ }^{46}$ These results support direct or indirect interactions between the HCV IRES and the cytoskeleton, but do not assign a function to the interactions.

Several proteins thought to be involved in signal transduction pathways were identified in the HCV IRES affinity extracts. The protein FHOS is discussed above. The UNR interacting protein MAWD was also identified; its overexpression constitutively activates MAP kinase and promotes anchorage-independent cell growth, and it is frequently overexpressed in breast cancer. ${ }^{47}$ The HCV core protein is also known to activate MAP kinase. ${ }^{48-50}$ Further work will be necessary to examine the 


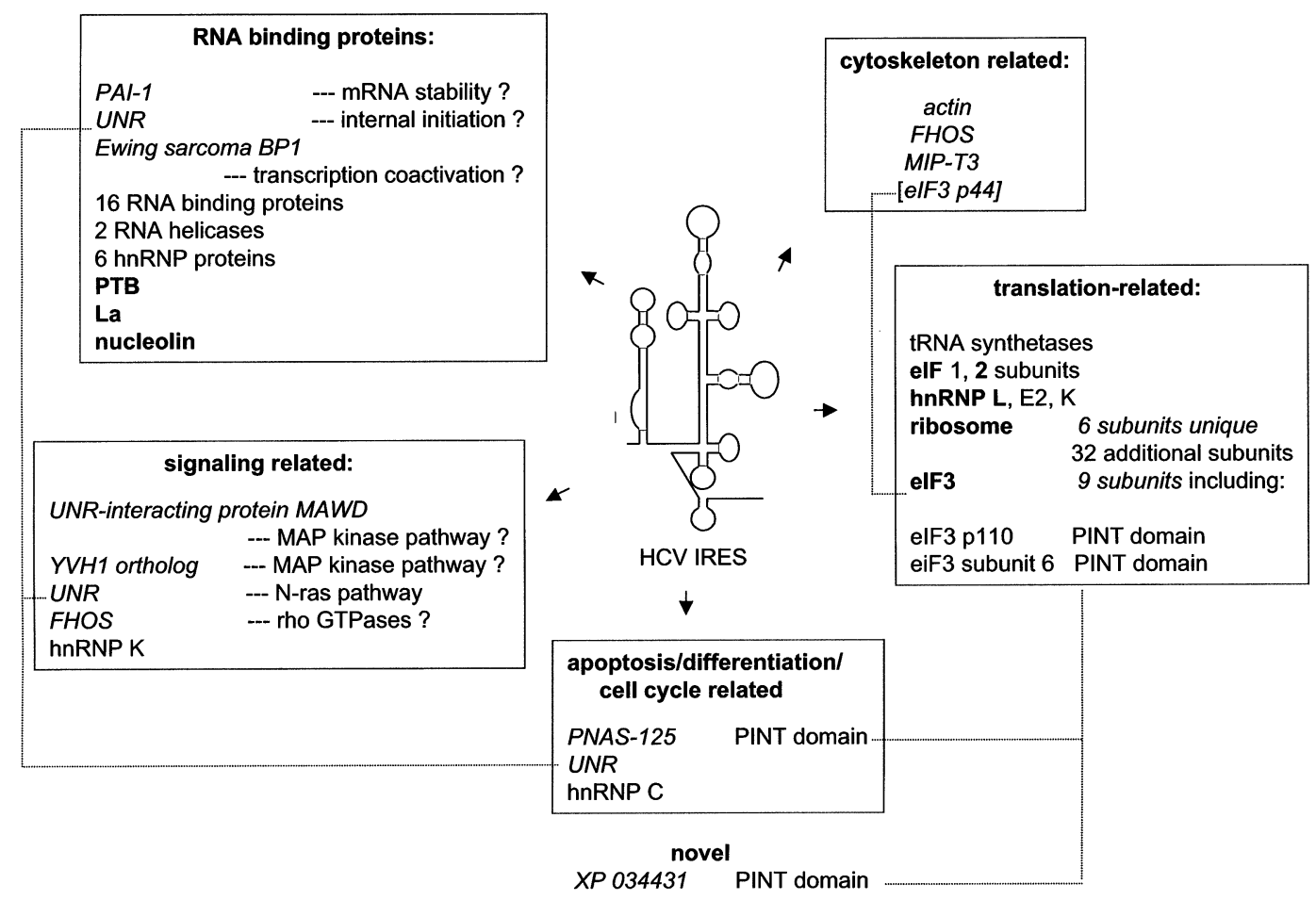

Figure 4. Summary of HCV IRES interacting proteins identified by affinity mass spectrometry. Known interacting proteins are in bold. Proteins interacting with the HCV IRES but not the reversed complementary IRES or a vector RNA control are indicated in italics. The observed interacting proteins can be placed in several different functional categories as indicated in boxes. New interactions, which will require further study to examine their functional importance, involve links between the HCV IRES and the cytoskeleton, cellular signaling, and perhaps apoptosis and cell cycle regulation.

relationship between IRES function, MAP kinase signaling, and HCV-associated liver diseases such as hepatocellular carcinoma. The UNR protein negatively regulates N-ras expression. ${ }^{51}$ $\mathrm{N}$-ras controls apoptosis, differentiation, and the cell cycle, ${ }^{52}$ and could possibly, along with hnRNP C (below), be linked to the observed cell cycle dependence of HCV translation. ${ }^{53}$ These results suggest a further investigation of the role of these identified proteins in HCV IRES function.

We have also discovered in the HCV affinity extract a number of RNA binding proteins, several of which have been discussed above, in addition to ribosomal or elF3 proteins. Some bind only the HCV IRES, while others also bind control RNAs. One is the UNR protein, which contains 5 cold-shock RNA binding domains $\mathrm{s}^{37,54}$ and is required for the internal initiation of human rhinovirus RNA translation. ${ }^{55}$ The WD-repeat UNR-interacting protein MAWD was also isolated. UNR, UNR-interacting protein, poly $(\mathrm{rC})$ binding proteins 1 and 2 , and hnRNP $K$, all observed here with relative abundances within a $\sim 3$-fold range, stimulate in vitro and in vivo activity of the c-myc cellular IRES, 56 and could potentially play a similar role for the HCV IRES. UNR and PTB, suggested to act in combination as RNA chaperones that change the structure of the Apaf-1 cellular IRES to permit translation initiation, ${ }^{57}$ were both observed here with similar protein abundance indices. Other IRES-unique RNA binding proteins observed here do not have assigned functions in IRES systems. One is the Ewing sarcoma breakpoint region 1 protein EWS, which may shuttle from the nucleus to the cell surface ${ }^{58}$ and function as a transcriptional cofactor with CBP/ p300.59 A second is the plasminogen activator inhibitor-1 (PAI1) mRNA binding protein, which binds chromodomain helicase DNA binding protein 3 , and may confer CAMP regulation of PAl-1 mRNA stability. ${ }^{60}$ The most abundant RNA binding proteins present (based on protein abundance indices) include poly ( $\mathrm{rC}$ ) binding protein 2, CRDBP, and IGF-II binding proteins 2 and 3 . The relative abundances of RNA binding proteins span an $\sim 18$-fold range, making inference of a single type of bound complex difficult.

We have also isolated a large number of proteins that bind both the HCV IRES and a reversed IRES control sequence, suggesting they are not interacting in an IRES structure- or sequence-specific fashion. Nonetheless, some could play interesting roles in IRES biology. The confirmation of HCV IRES binding to the nucleolar RNA binding protein and RNA and DNA helicase nucleolin, which is involved in ribosome biogenesis and control of cell proliferation and growth, ${ }^{61}$ is particularly interesting in view of the proposed role of the nucleolus as a gateway for viral infection and site of replication for many viruses including DNA and RNA viruses, and retroviruses. $^{62}$ The discovery of a variety of elongation factors, ribosomal proteins, and tRNA synthetases is consistent with the function of the IRES in protein production. HnRNPS are involved in transcription, pre-mRNA processing, mature mRNA transport to the cytoplasm, and translation; a total of 11 different hnRNPs were isolated here. HnRNP $K^{63}$ stimulation of c-myc IRES translation was noted above. HnRNP L may enhance the translation of some IRES-dependent mRNAs. ${ }^{64}$ HnRNP E2 enhances poliovirus mRNA translation. ${ }^{64} \mathrm{HnRNP}$ $C$, also identified here, may modulate c-myc IRES translation in a cell cycle-dependent fashion. ${ }^{65} \mathrm{HnRNP} U$, one of the most prominent hnRNPs present, binds the leader RNA sequence of vesicular stomatitis virus, and may play a role in the life cycle of this virus. ${ }^{66}$ Their identification here as interacting proteins for the HCV IRES suggests these hnRNPs could play similar roles for HCV. 


\section{Conclusions}

The application of mass spectrometry-based shotgun peptide sequencing to quadruplicate hepatitis C IRES affinity extracts has confirmed the identification of a number of known HCV IRES interacting proteins, and has significantly expanded the number and types of proteins which interact with this functional RNA. Some identified proteins binding the HCV IRES, but not control RNAs, are known to bind to other cellular or pathogen IRESs, whereas others have not to our knowledge been reported to bind to any IRES. A large number of proteins were identified that are less specifically bound, but which could still have interesting roles in HCV IRES biology, such as nucleolin. This IRES binds proteins in several defined functional classes. Some proteins are members of more than one functional class, suggesting a possible linkage between these functions. This expanded view of cellular interacting proteins suggests new cellular functional areas that might be involved in IRES biology. Further examination of the coupling of some of the identified proteins to IRES function or HCV replication, by overexpression or by specific deletion of individual proteins using siRNA, may identify drug targets for hepatitis C. The "fingerprint" of interacting partners derived here may be useful for further comparisons, for example between the HCV IRES and other pathogen or host cell IRESs, or between different $\mathrm{HCV}$ genotypes, to examine the relation between differences in function and changes in cellular interacting proteins.

\section{References}

(1) World Health Organization. Global surveillance and control of hepatitis C: report of a WHO consultation organized in collaboration with the Viral Hepatitis Prevention Board, Antwerp, Belgium. J. Viral Hepat. 1999, 6, 35-47.

(2) El-Serag, H. Hepatocellular carcinoma and hepatitis $C$ in the United States. Hepatology 2002, 36, S74-83.

(3) Koike, K.; Moriya, K.; Kimura, S. Role of hepatitis C virus in the development of hepatocellular carcinoma: transgenic approach to viral hepatocarcinogenesis. J. Gastroenterol. Hepatol. 2002, 17, $394-400$.

(4) Tsukiyama-Kohara, K.; lizuka, N.; Kohara, M.; Nomoto, A. Internal ribosome entry site within hepatitis C virus RNA. J. Virol. 1992, 66, 1476-1483.

(5) Buratti, E.; Tisminetzky, S.; Zotti, M.; Baralle, F. Functional analysis of the interaction between HCV $5^{\prime}$ UTR and putative subunits of eukaryotic translation initiation factor elF3. Nucleic Acids Res. 1998, 26, 3179-3187.

(6) Kruger, M.; Beger, C.; Li, Q.; Welch, P.; Tritz, R.; Leavitt, M.; Barber, J. R.; Wong-Staal, F.Identification of elf $2 \gamma$ and elF $2 \gamma$ as cofactors of hepatitis $C$ virus internal ribosome entry sitemediated translation using a functional genomics approach. Proc. Natl. Acad. Sci. U.S. A. 2000, 97 (15), 8566-8571.

(7) Kolupaeva, V.; Pestova, T.; Hellen, C. An enzymatic footprinting analysis of the interaction of ribosomal subunits with the internal ribosomal entry site of hepatitis C virus. J. Virol. 2000, 74, 62426250.

(8) Hellen, C.; Pestova, T. Translation of hepatitis C virus RNA. J. Viral. Hepat. 1999, 6, 79-87.

(9) Kozak, M. The scanning model for translation: an update. J. Cell Biol. 1989, 108, 229-241.

(10) Chung, R.; Kaplan, L. Heterogeneous nuclear ribonucleoprotein I (hnRNP-I/PTB) selectively binds the conserved 3 'terminus of hepatitis C viral RNA. Biochem. Biophys. Res. Commun. 1999, 254, 351-362.

(11) Isoyama, T.; Kamoshita, N.; Yasui, K.; Iwai, A.; Shiroki, K.; Toyoda, H.; Yamada, A.; Takasaki, Y.; Nomoto, A. Lower concentration of La protein required for internal ribosome entry on hepatitis C virus RNA than on poliovirus RNA. J. Gen. Virol. 1999, 80, 23192327.

(12) Hahm, B.; Kim, Y.; Kim, J.; Kim, T.; Jang, S. Heterogeneous nuclear ribonucleoprotein $L$ interacts with the 3 ' border of the internal ribosomal entry site of hepatitis C virus. J. Virol. 1998, 72, 87828788.
(13) Kruger, M.; Beger, C.; Welch, P.; Barber, J.; Manns, M.; WongStaal, $F$. Involvement of proteasome $\alpha$-subunit PSMA7 in hepatitis $\mathrm{C}$ virus internal ribosome entry site-mediated translation. Mol. Cell Biol. 2001, 21, 8357-8364.

(14) Izumi, R. E.; Valdez, B.; Banerjee, R.; Srivastava, M.; Dasgupta, A. Nucleolin stimulates viral internal ribosome entry site-mediated translation. Virus Res. 2001, 76, 17-29.

(15) Hunt, D.; Buko, A.; Ballard, J.; Shabanowitz, J.; Giordani, A. Sequence analysis of polypeptides by collision activated dissociation on a triple quadrupole mass spectrometer. Biomed. Mass Spectrom. 1981, 8, 397-408.

(16) McCormack, A.; Schieltz, D.; Goode, B.; Yang, S.; Barnes, G.; Drubin, D, Yates, J., III. Direct analysis and identification of proteins in mixtures by LC/MS/MS and database searching at the low-femtomole level. Anal. Chem. 1997, 69, 767-776.

(17) Neubauer, G.; Gottschalk, A.; Fabrizio, P.; Seraphin, B.; Luhrmann R.; Mann, M. Identification of the proteins of the yeast U1 small nuclear ribonucleoprotein complex by mass spectrometry. Proc. Natl. Acad. Sci. U.S.A. 1997, 94, 385-390.

(18) Link, A.; Eng, J.; Schieltz, D.; Carmack, E.; Mize, G.; Morris, D.; Garvik, B.; Yates, J. III. Direct analysis of protein complexes using mass spectrometry. Nat. Biotech. 1999, 17, 678-682.

(19) Rout, M.; Aitchison, J.; Suprapto, A.; Hjertaas, K.; Zhao, Y.; Chait, $B$. The yeast nuclear pore complex: composition, architecture, and transport mechanism. J. Cell Biol. 2000, 148, 635-651.

(20) Gavin, A.; Bosche, M.; Krause, R.; Grandi, P.; Marzioch, M.; Bauer, A.; Schultz, J.; Rick, J.; Michon, A.; Cruciat, C.; Remor, M.; Hofert, C.; Schelder, M.; Brajenovic, M.; Ruffner, H.; Merino, A.; Klein K.; Hudak, M.; Dickson, D.; Rudi, T.; Gnau, V.; Bauch, A.; Bastuck, S.; Huhse, B.; Leutwein, C.; Heurtier, M.; Copley, R.; Edelmann, A.; Querfurth, E.; Rybin, V.; Drewes, G.; Raida, M.; Bouwmeester T.; Bork, P.; Seraphin, B.; Kuster, B.; Neubauer, G.; Superti-Furga, G. Functional organization of the yeast proteome by systematic analysis of protein complexes. Nature 2002, 415, 141-147.

(21) Ho, Y.; Gruhler, A.; Heilbut, A.; Bader, G.; Moore, L.; Adams, S.; Millar, A.; Taylor, P.; Bennett, K.; Boutilier, K.; Yang, L.; Wolting C.; Donaldson, I.; Schandorff, S.; Shewnarane, J.; Vo, M.; Taggart, J.; Goudreault, M.; Muskat, B.; Alfarano, C.; Dewar, D.; Lin, Z.; Michalickova, K.; Willems, A.; Sassi, H.; Nielsen, P.; Rasmussen, K.; Andersen, J.; Johansen, L.; Hansen, L.; Jespersen, H.; Podtelejnikov, A.; Nielsen, E.; Crawford, J.; Poulsen, V.; Sorensen, B.; Matthiesen, J.; Hendrickson, R.; Gleeson, F.; Pawson, T.; Moran, M.; Durocher, D.; Mann, M.; Hogue, C.; Figeys, D.; Tyers, M. Systematic identification of protein complexes in Saccharomyces cerevisiae by mass spectrometry. Nature 2002, 415, 180183.

(22) Gururaja, T.; Li, W.; Bernstein, J.; Payan, D. G.; Anderson, D. C. Use of MEDUSA-based data analysis and capillary HPLC-ion trap mass spectrometry to examine complex immunoaffinity extracts of RbAp48. J. Proteome Res. 2002, 1, 253-261.

(23) Washburn, M.; Wolters, D.; Yates, J., III. Large scale analysis of the yeast proteome by multidimensional protein identification technology. Nature Biotechnology 2002, 19, 242-247.

(24) Andersen, J.; Lyon, C.; Fox, A.; Leung, A.; Lam, Y.; Steen, H.; Mann, M.; Lamond, A. Directed proteomic analysis of the human nucleolus. Curr. Biol. 2002, 12, 1-11.

(25) Gururaja, T.; Li, W.; Noble, W. S.; Payan, D.; Anderson, D. C. Multiple functional categories of proteins identified in an in vitro cellular ubiquitin affinity extract using shotgun peptide sequencing. J. Proteome Res. 2003, 2, 394-404.

(26) Eng, J.; McCormack, A.; Yates, J., III. An approach to correlate tandem mass spectral data of peptides with amino acid sequences in a protein database. J. Am. Soc. Mass Spectrom. 1994, 5, 976-989.

(27) Anderson, D. C.; Li, W.; Payan, D.; Noble, W. S. A new algorithm for the evaluation of shotgun peptide sequencing in proteomics: Support vector machine classification of peptide MS/MS spectra and SEQUEST scores. J. Proteome Res. 2003, 2, 137-146.

(28) Lohmann, V.; Korner, F.; Koch, J. O.; Herian, U.; Theilmann, L.; Bartenschlager, R. Replication of subgenomic hepatitis $C$ virus RNAs in a hepatoma cell line. Science 1999, 285, 110-113.

(29) Shevchenko, A.; Wilm, M.; Vorm, O.; Mann, M. Mass spectrometric sequencing of proteins silver-stained polyacrylamide gels. Anal. Chem. 1996, 68, 850-858.

(30) Rappsilber, J.; Ryder, U.; Lamond, A.; Mann, M. Large-scale proteomic analysis of the human spliceosome. Genome Res. 2002, $12,1231-1245$.

(31) Reynolds, J.; Kaminski, A.; Kettinen, H.; Grace, K.; Clarke, B.; Carroll, A.; Rowlands, D.; Jackson, R.Unique features of internal initiation of hepatitis C virus RNA translation. EMBO J. 1995, 14, 6010-6020. 
(32) Lu, H.; Wimmer, E. Poliovirus chimeras replicating under the translational control of genetic elements of hepatitis $C$ virus reveal unusual properties of the internal ribosomal entry site of hepatitis C virus. Proc. Natl. Acad. Sci. U.S.A. 1996, 93, 1412-1417.

(33) Kieft, J.; Zhou, K.; Jubin, R.; Doudna, J. Mechanism of ribosome recruitment by hepatitis C IRES RNA. RNA 2001, 7, 194206.

(34) Lukavsky, P.; Kim, I.; Otto, G.; Puglisi, J. Structure of HCV IRES domain II determined by NMR. Nat. Struct. Biol. 2003, 10, 10331038.

(35) Sizova, D.; Kolupaeva, V.; Pestova, T.; Shatsky, I.; Hellen, C. Specific interaction of eukaryotic translation initiation factor 3 with the $5^{\prime}$ nontranslated regions of hepatitis $C$ virus and classical swine fever virus RNAs. J Virol. 1998, 72, 4775-4782.

(36) Okazaki I.; Moss, J. Mono-ADP-ribosylation: a reversible posttranslational modification of proteins. Adv. Pharmacol. 1996, 35, 247-280.

(37) Jacquemin-Sablon, H.; Triqueneaux, G.; Deschamps, S.; le Maire, M.; Doniger, J.; Dautry, F. Nucleic acid binding and intracellular localization of unr, a protein with five cold shock domains. Nucleic Acids. Res. 1994, 22, 2643-2650.

(38) Westendorf, J.The formin/diaphanous-related protein, FHOS, interacts with Racl and activates transcription from the serum response element. J. Biol. Chem. 2001, 276, 46 453-46 459.

(39) Saiz, J.; Lopez de Quinto, S.; Ibarrola, N.; Lopez-Labrador, F.; Sanchez-Tapias, J.; Rodes, J.; Martinez-Salas, E. Internal initiation of translation efficiency in different hepatitis $C$ genotypes isolated from interferon treated patients. Arch. Virol. 1999, 144, 215-229.

(40) Thelu, M.; Drouet, E.; Hilleret, M.; Zarski, J. Lack of clinical significance of variability in the internal ribosome entry site of hepatitis C virus. J. Med. Virol. 2004, 72, 396-405.

(41) Gururaja, T.; Li, W.; Catalano, S.; Bogenberger, J.; Zheng, J.; Keller, B.; Vialard, J.; Janicot, M.; Li, L.; Hitoshi, Y.; Payan, D.; Anderson, D. C. Cellular interacting proteins of functional screen-derived antiproliferative and pro-apoptotic peptides discovered using mass spectrometry-based shotgun peptide sequencing. Chem. Biol. 2003, 10, 975-987.

(42) Fukushi, S.; Okada, M.; Stahl, J.; Kageyama, T.; Hoshino, F.; Katayama, K. Ribosomal protein S5 interacts with the internal ribosomal entry site of hepatitis C virus. J. Biol. Chem. 2001, 276, 20 824-20 826.

(43) Hou, C. L.; Tang, C.; Roffler, S.; Tang, T. Protein 4.1R binding to elF3-p44 suggests an interaction between the cytoskeletal network and the translation apparatus. Blood 2000, 96, 747-753.

(44) Bost, A.; Venable, D.; Liu, L.; Heinz, B. Cytoskeletal requirements for hepatitis $\mathrm{C}$ virus (HCV) RNA synthesis in the HCV replicon cell culture system. J. Virol. 2003, 77, 4401-4408.

(45) Westendorf, J.; Mernaugh, R.; Hiebert, S. Identification and characterization of a protein containing formin homology (FHI/ FH2) domains. Gene 1999, 232, 173-182.

(46) Ling, L.; Goeddel, D. MIP-T3, a novel protein linking tumor necrosis factor receptor-associated factor 3 to the microtubule network. J. Biol. Chem. 2000, 275, 23 852-23 860.

(47) Matsuda, S.; Katsumata, R.; Okuda, T.; Yamamoto, T.; Miyazaki, K.: Senga, T.; Machida, K.; Thant, A.; Nakatsugawa, S.; Hamaguchi, M. Molecular cloning and characterization of human MAWD, a novel protein containing WD-40 repeats frequently overexpressed in breast cancer. Cancer Res. 2000, 60, 13-17.

(48) Tsuchihara, K.; Hijikata, M.; Fukuda, K.; Kuroki, T.; Yamamoto, N. Shimotohno, K. Hepatitis C virus core protein regulates cell growth and signal transduction pathway transmitting growth stimuli. Virology 1999, 258, 100-107.

(49) Hayashi, J.; Aoki, H.; Kajino, K.; Moriyama, M.; Arakawa, Y.; Hino, $O$. Hepatitis $C$ virus core protein activates the MAPK/ERK cascade synergistically with tumor promoter TPA, but not with epidermal growth factor or transforming growth factor $\alpha$. Hepatology $\mathbf{2 0 0 0}$ 32, 958-961.

(50) Giambartolomei, S.; Covone, F.; Levrero, M.; Balsano, C. Sustained activation of the Raf/MEK/Erk pathway in response to EGF in stable cell lines expressing the Hepatitis C Virus (HCV) core protein. Oncogene 2001, 20, 2606-2610.

(51) Boussadia, O.; Amiot, F.; Cases, S.; Triqueneaux, G.; JacqueminSablon, H.; Dautry, F. Transcription of unr (upstream of N-ras) down-modulates $\mathrm{N}$-ras expression in vivo. FEBS Lett. 1997, 420, 20-24.

(52) Crespo, P.; Leon, J. Ras proteins in the control of the cell cycle and cell differentiation. Cell Mol. Life Sci. 2000, 57, 1613-1636.

(53) Honda, M.; Kaneko, S.; Matsushita, E.; Kobayashi, K.; Abell, G.; Lemon, $\mathrm{S}$. Cell cycle regulation of hepatitis $C$ virus internal ribosomal entry site-directed translation. Gastroenterology 2000, $118,152-162$.

(54) Ferrer, N.; Garcia-Espana, A.; Jeffers, M.; Pellicer, A. The unr gene: evolutionary considerations and nucleic acid-binding properties of its long isoform product. DNA Cell Biol. 1999, 18, 209-218.

(55) Hunt, S. L.; Hsuan, J.; Totty, N.; Jackson, R. Unr, a cellular cytoplasmic RNA-binding protein with five cold-shock domains, is required for internal initiation of translation of human rhinovirus RNA. Genes Dev. 1999, 13, 437-448.

(56) Evans, J.; Mitchell, S.; Spriggs, K.; Ostrowski, J.; Bomsztyk, K.; Ostarek, D.; Willis, A. Members of the poly ( $\mathrm{rC}$ ) binding protein family stimulate the activity of the c-myc internal ribosome entry segment in vitro and in vivo. Oncogene 2003, 22, 8012-8020.

(57) Mitchell, S.; Spriggs, K.; Coldwell, M.; Jackson, R.; Willis, A. The Apaf-1 internal ribosome entry segment attains the correct structural conformation for function via interactions with PTB and unr. Mol. Cell 2003, 11, 757-771.

(58) Belyanskaya, L.; Gehrig, P.; Gehring, H. Exposure on cell surface and extensive arginine methylation of EWS protein. J. Biol. Chem. 2001, 276, $18681-18687$.

(59) Rossow, K.; Janknecht, R. The Ewing's sarcoma gene product functions as a transcriptional activator. Cancer Res. 2001, 61, 2690-2695.

(60) Heaton, J.; Dlakic, W.; Dlakic, M.; Gelehrter, T. Identification and cDNA cloning of a novel RNA-binding protein that interacts with the cyclic nucleotide-responsive sequence in the Type-1 plasminogen activator inhibitor mRNA. J. Biol. Chem. 2001, 276, 3341-3347.

(61) Srivastava, M.; Pollard, H. Molecular dissection of nucleolin's role in growth and cell proliferation: new insights. FASEB J. 1999, 13, 1911-1922.

(62) Hiscox, J. The nucleolus- a gateway to viral infection? Arch. Virol. 2002, 147, 1077-1089.

(63) Chen, H.; Lin, W.; Tsay, Y.; Lee, S.; Chang, C. An RNA helicase DDX1, interacting with poly $(A)$ RNA and heterogeneous nuclear ribonucleoprotein K. J. Biol. Chem. 2002, 277, $40403-40409$.

(64) Kim, J.; Hahm, B.; Kim, Y.; Choi, M.; Jang, S. Protein-protein interaction among hnRNPs shuttling between nucleus and cytoplasm. J Mol. Biol. 2000, 298, 395-405.

(65) Kim, J.; Paek, K.; Choi, K.; Kim, T.; Hahm, B.; Kim, K.; Jang, S. Heterogeneous nuclear ribonucleoprotein $C$ modulates translation of c-myc mRNA in a cell cycle phase-dependent manner. Mol. Cell Biol. 2003, 23, 708-720.

(66) Gupta, A.; Drazba, J.; Banerjee, A. Specific interaction of heterogeneous nuclear ribonucleoprotein particle $U$ with the leader RNA sequence of vesicular stomatitis virus. J. Virol. 1998, 72, 8532-8540.

PR0499592 